\title{
“БОРЬБА ИНТЕГРАЦИЙ” НА ПОСТСОВЕТСКОМ ПРОСТРАНСТВЕ: ГУМАНИТАРНОЕ ИЗМЕРЕНИЕ
}

\begin{abstract}
Аннотация. В статье рассмотрены процессы взаимодействия различных интеграционных проектов на постсоветском пространстве в контексте формирования Евразийского экономического союза. Дан анализ причин развития ситуации в регионе Восточной Европы в логике “борьбы интеграций” вместо “интеграции интеграций”. Приоритетное внимание уделено тенденциям в сфере гуманитарного присутствия Евросоюза и Китая на постсоветском пространстве, сделана оценка эффективности отдельных составляющих данной политики. Работа вносит вклад в изучение современных инструментов и тенденций в гуманитарном сотрудничестве. Сделан вывод о том, что гуманитарное измерение есть неотъемлемый элемент обеспечения безопасности. Сформулированы рекомендации о необходимости расширения гуманитарного сотрудничества в ЕАЭС и СНГ, обоснована востребованность обновления подходов для повышения конкурентоспособности этих организаций.
\end{abstract}

Ключевые слова: постсоветское пространство, интеграция, безопасность, гуманитарное сотрудничество, мягкая сила, Евразийский экономический союз, Европейский союз, Китай, США, НАТО.

В Восточной Европе и на постсоветском пространстве усиливается “борьба интеграций”. США и Западная Европа работают преимущественно в многосторонних форматах НАТО и ЕС (программа "Восточное партнёрство", ВП). Китай действует в рамках формата “16+1" (саммиты "Китай - Восточная Европа") и “под зонтиком" инициативы "Пояс и путь", фокусируясь на двусторонних отношениях. В ходе этой работы различными путями решаются задачи по наращиванию влияния в сфере политики и безопасности, лоббированию выгодных экономических, инфраструктурных проектов. Всё более заметными становятся изменения и в гуманитарной составляющей: системная работа с общественнополитическими, экспертно-научными и медийными кругами (в особенности с мо-

(C) Смирнов Вадим Анатольевич - кандидат политических наук, докторант Института Европы РАН. Адрес: 125009, Россия, Москва, ул. Моховая, д. 11-3. E-mail: vsmirnov@kantiana.ru

DOI: http://dx.doi.org/10.15211/soveurope620185161 
лодыми лидерами), продвижение собственной информационной, ценностной повестки дня.

Наиболее острая конкуренция разворачивается в нескольких сферах: технические стандарты и технологии (в сфере безопасности, управления и др.), торговоэкономические соглашения (зоны свободной торговли и др.), логистические коридоры и контроль над территориями (в том числе de facto экстерриториальная юрисдикция на логистических объектах, лабораториях, индустриальных и сельскохозяйственных территориях), образование (от начального - до высшего, а также отраслевое, военное и религиозное), информационная сфера (работа с лидерами мнений, экспертами, СМИ, запуск информационных кампаний) и общественный сектор (организации гражданского общества и публичной дипломатии).

\section{Стратегические приоритеты евразийского проекта}

Позиции России на постсоветском пространстве укрепились в результате создания Евразийского экономического союза (ЕАЭС). Возникла динамичная общая повестка дня, площадка для диалога и постоянной совместной работы административных структур. Углубление и расширение интеграции в рамках ЕАЭС заявлено в качестве одного из ключевых приоритетов в Концепции внешней политики России, принятой в 2016 г. В ней отмечено: "ЕАЭС способен сыграть важную роль в деле гармонизации интеграционных процессов в Европейском и Евразийском регионах" [Концепция внешней политики РФ, 2016].

В статье, опубликованной накануне саммита АТЭС 10-11 ноября 2017 г., президент России В.В. Путин заявил: “Хочу отдельно отметить нашу идею по созданию Большого евразийского партнёрства. Предложили формировать его на базе Евразийского экономического союза и китайской инициативы “Один пояс - один путь” [XXV саммит АТЭС в Дананге..., 2017]. Предлагаемый интеграционный проект “открыт для присоединения других участников”. Помимо торговых, экономических аспектов взаимодействия Российской Федерацией выдвигается предложение интенсифицировать сотрудничество и в гуманитарной сфере. "Предлагаем больше внимания уделять социально-гуманитарной сфере. Отмечу важность оказания содействия высшим учебным заведениям наших стран в налаживании межвузовских связей, реализации совместных учебных и научных программ, расширении студенческих обменов, повышении академической мобильности", отметил президент России В.В. Путин в своём обращении в связи с председательством Российской Федерации в органах ЕАЭС в 2018 г. [Обращение Президента России..., 2018].

Евразийский экономический союз не рассматривается обособленно от макрорегиональных интеграционных процессов в Европе и Евразии, встраивание в данные процессы видится как стратегическая задача, создающая мощный ресурс экономического развития [70-я сессия Генеральной Ассамблеи ООН..., 2015]. В 2018 г. подписано соглашение о сотрудничестве ЕАЭС с Китаем, остаются открытыми двери и для диалога с ЕС. Как отмечает Ал.А. Громыко, в случае признания бесперспективности трансформации ЕС в государство или “неоимперию” появится возможность возвращения к идее партнёрства России и Евросоюза. Однако в отсутствие общеевропейской системы безопасности “политика ЕС продолжает оставаться фактором в потенциале раскручивания конфронтации с Россией”

Современная Европа, 2018, №6 
[Громыко, 2016: 16]. Вместе с тем усилия по “встраиванию” в макрорегиональные процессы окажутся под вопросом, если будут осуществляться без укрепления экономических, социальных и культурных связей внутри ЕАЭС и СНГ, что приведёт к фрагментации общего пространства безопасности. В 2015 г., вскоре после начала работы Евразийского экономического союза, секретарь Совета безопасности России Н.П. Патрушев констатировал: "В современном меняющемся мире некоторые страны усматривают в ЕАЭС потенциально серьёзного конкурента в мировой экономике и проводят деструктивную деятельность по срыву интеграционных процессов" [Состоялась рабочая поездка..., 2015]. ЕАЭС сегодня единственный пример формата в постсоветском регионе, где решения принимаются консенсусом. Спорное решение Евразийской экономической комиссии может быть вынесено участником ЕАЭС на уровень Высшего евразийского экономического совета, где каждая страна обладает правом вето независимо от размера и доли в экономике союза. Что касается Восточного партнёрства ЕС, то его администрированием занимаются из Брюсселя, а секретариат саммита "Китай-Восточная Европа" (“16+1”) располагается в МИД КНР. "Пакет опций” для партнёров КНР в рамках инициативы "Пояс и путь" также формируется Пекином.

ЕАЭС достиг заметных успехов в создании общего рынка труда, снятии таможенных барьеров. Удельный вес взаимной торговли стран ЕАЭС в совокупной внешней торговле вырос с 12,3\% в 2012 г. до 14,5\% в 2017 г. ${ }^{1}$ Вместе с тем, он остается скромным по сравнению с ЕС, где данный показатель превышает $60 \%$. В рамках ЕАЭС не редки торговые споры, связанные как с влиянием санкций на общее таможенное пространство (споры России и Белоруссии), так и с внутренними противоречиями (Казахстан и Киргизия). Пока не решена задача опережающего формирования новых высокотехнологичных торгово-промышленных цепочек. Наблюдается прогресс в выработке коллективной переговорной позиции в отношениях с третьими странами. Торгово-экономические соглашения заключены ЕАЭС с Вьетнамом, Ираном и Китаем. Переговоры и консультации ведутся с несколькими десятками государств.

\section{Структурная конфронтация в Восточной Европе}

Вектор выстраивания внешних связей ЕАЭС приобретает отчетливую юговосточную направленность. На Западе ЕАЭС был преимущественно расценен как “геополитический” и “конкурирующий” проект [Eurasian Economic Union..., 2017], диалога не получается, вместо “интеграции интеграций” выкристаллизовывается “борьба интеграций”. Своего рода декларацией конфронтационной логики отношений стало заявление главы Европейского совета Д. Туска: “стратегия России нацелена на ослабление Евросоюза" [Remarks by President Donald Tusk, 2016]. В экспертных кругах ЕС преобладают оценки ЕАЭС как “охранительного проекта", “протекционистской меры против глобализации и барьера против влияния других акторов", подчёркивается его направленность на контроль территории [Kaczmarski, 2017: 1357], при этом реальные процессы экономической интеграции

${ }^{1}$ Статистика внешней и взаимной торговли товарами EAЭC. URL: http://www.eurasiancommission.org/ru/act/integr_i_makroec/dep_stat/tradestat/Pages/default.aspx (дата обращения: 14.08.2018)

Современная Европа, 2018, №6 
и нормотворчества часто выносятся за скобки анализа. Вместе с тем встречаются критические оценки ставших после 2014 г. традиционными призывов к руководству ЕС принять геополитическую логику “новой холодной войны” в отношениях с Россией. "ЕС является (и всегда был) геополитическим актором" и посредством таких "геостратегий как Восточная политика соседства и Восточное партнёрство оказывает влияние на территории за пределами своих границ" [Browning, 2018: 113]. Российские эксперты отмечают шаги ЕС по торможению развития Евразийского экономического союза путём “ограничения его деятельности и ослабления ресурсной базы” [Кондратьева, 2018: 62].

Официальная позиция ЕС заключается в том, что взаимодействие с ЕАЭС блокирует украинский кризис. Но контакты между ЕК и ЕЭК не развивались и до 2014 г. Учитывая высокую степень координации политики ЕС и США на постсоветском пространстве и глубокое укоренение инфраструктуры НАТО в Европе, одним из важнейших факторов стал тупик в российско-американских отношениях. Его прямые предпосылки сложились до государственного переворота на Украине, после неудавшейся "перезагрузки” двусторонних отношений. Сказываются и внутренние проблемы ЕС и евроатлантического сообщества в целом, сопряженные с этим попытки консолидации ссылками на внешнюю угрозу. Набирающие силу тенденции изменения глобального баланса сил и протекционизма, повышающийся градус внутриполитического противостояния в США делают маловероятным выход в обозримом будущем на устойчивые форматы согласования политики России и Запада на постсоветском пространстве.

Противостояние в Восточной Европе и на постсоветском пространстве приобретает структурный характер. Принятие Совместной декларации НАТО-ЕС в 2016 г. обусловливает более тесную, уже формальную увязку военнополитических установок Евросоюза с альянсом [Joint Declaration, 2016]. В Польше и Румынии продолжается развёртывание системы ПРО, ЕС ведёт работу по модернизации транспортной инфраструктуры и снятию бюрократических барьеров для свободного передвижения войск США и НАТО к границам Беларуси и России (т.н. “военный Шенген”), наращиваются усилия по повышению оперативной совместимости сил НАТО и отдельных стран ЕАЭС.

Повышается интенсивность военных мероприятий и учений. Так, финансирование программы по усилению присутствия США в Европе (European Deterrence Initiative), инициированной ещё администрацией Б. Обамы в 2014 г., возросло с 1 млрд долл. в 2014 г. до 4,8 млрд долл. в 2018 г. На 2019 г. Пентагон запросил увеличение бюджета до 6,5 млрд долл. ${ }^{2}$ Продолжается последовательная политика по укреплению американских позиций на Украине. США выделили Киеву в

\footnotetext{
${ }^{1}$ Евразийская экономическая комиссия создана на основании договора "О Евразийской экономическая комиссии”, заключённого 18 ноября 2011 г. между Республикой Беларусь, Республикой Казахстан и Российской Федерацией. Наряду с новыми полномочиями в сфере наднационального регулирования ЕЭК были переданы полномочия учреждённой в 2007 г. Комиссии Таможенного союза.

${ }^{2}$ U.S. Increases Commitment to Deterrence with EDI Request // U.S. European Command. URL: www.eucom.mil/media-library/article/36241/u-s-increases-commitment-to-deterrence-with-edirequest
}

Современная Европа, 2018, №6 
2017 г. 650 млн долл. на подготовку, оборудование и снабжение украинских вооружённых сил и сил безопасности [Гегелашвили, 2018: 100]. Параллельно наращивается политическое и информационное давление на Сербию и Молдавию. В 2017 г. в Кишинёве открыт офис НАТО. С 2015 г. учения с участием Альянса стали на территории Молдавии регулярными, развернуто системное взаимодействие в сфере военно-технического сотрудничества, что свидетельствует о de facto постепенной интеграции страны в военно-политическое пространство НАТО. На этом фоне в Беларуси западные фонды и НКО предпринимают усилия по популяризации идеи военно-политического нейтралитета. Ситуация в западной части постсоветского пространства показывает, что основные усилия Запада в рамках “борьбы интеграций” концентрируются в гуманитарной области с дальнейшим выходом в политическую и военно-техническую сферы. В этой логике гуманитарная составляющая всё больше становится элементом политики не столько поддержания “исторических связей”, столько обеспечения безопасности.

Украинский кризис не привёл к пересмотру политики ЕС и курса HATO, попрежнему направленных на расширение своего влияния на восток. Поступательное приближение военной инфраструктуры НАТО к российским границам и попустительство действиям стран, рассчитывавших вступить в альянс, приводят к размыванию или демонтажу различных форматов безопасности в Большой Европе [Громыко, 2018]. Вступление Черногории в НАТО в 2017 г., несмотря на отсутствие поддержки этого шага большинством населения страны, и заявление генерального секретаря альянса Й. Столтенберга летом 2018 г. о продолжении подготовки Грузии к вступлению в НАТО, свидетельствуют о неизменности подходов [Remarks by NATO Secretary General, 2018].

Соглашения об ассоциации с ЕС, помимо Украины, подписали Грузия и Молдавия. В каждой из этих стран развернута большая работа по переформатированию нормативно-правовой базы международного сотрудничества и общественного мнения. По официальным данным Госдепартамента США, до 3/4 от общих объёмов американских фондов содействия направляются в сферу безопасности, демократии и управления (для Украины $-72 \%$, Грузии $-69 \%^{1}$, Молдовы $-46 \%{ }^{2}$ ). Примечательно, что в новой Глобальной стратегии ЕС, принятой в 2016 г., содержится положение о том, что “мягкая и жёсткая сила" в политике Евросоюза “неразрывно связаны” [Shared Vision, 2016: 4] ${ }^{3}$. ЕС заявляет о том, что он корректирует взаимодействие со странами Восточного партнёрства и будет применять к ним индивидуальный подход. Однако общая политика, несмотря на все внутренние вызовы, остается без изменений. Как США и НАТО, ЕС по-прежнему стремится распространить своё влияние на восток без учёта связей стран постсоветского пространства с Россией. В среднесрочной перспективе жёсткая конкурен-

${ }^{1}$ United States Department of State. Office of the Coordinator of U.S. Assistance to Europe, Eurasia and Central Asia. Foreign Assistance Fact Sheet. Ukraine. April 2018. P. 1.

${ }^{2}$ United States Department of States. Office of the Coordinator of U.S. Assistance to Europe and Eurasia. Foreign Assistance Fact Sheet. Moldova. June 2014. P. 1.

${ }^{3}$ Shared Vision, Common Action: A Stronger Europe. A Global Strategy for the European Union's Foreign And Security Policy. 2016.URL:

http://eeas.europa.eu/archives/docs/top_stories/pdf/eugs_review_web.pdf

Современная Европа, 2018, №6 
ция и протекционизм будут определять экономические отношения Россия - EC на постсоветском пространстве. “Даже гипотетическое и маловероятное выполнение "Минска" уже не станет сигналом для перезагрузки и российско-европейского сближения” [Данилов, 2017: 18-19].

\section{Подходы Запада и Китая в гуманитарной сфере}

В рамках Восточного партнёрства ЕС делает ставку на новые технологии (например, продвижение своих цифровых стандартов или образовательных стандартов), активно развивает программы грантового финансирования, в том числе для малого бизнеса, интенсивно и на системной основе работает с кадрами (программы стажировок и переподготовки кадров, в т.ч. для органов власти). Чиновники ЕС стремятся усилить “видимость для простого населения" своих программ в странах ВП, с этой целью интенсивнее прибегая к инструментам различных информационных кампаний.

Какова успешность этой работы? С одной стороны, после распада СССР не стал успешным ни один “демократический транзит”. Более того, в политических системах восточноевропейских стран ЕС происходит своеобразная “эрозия евростандартов”, наиболее яркие примеры - Польша и Венгрия, которым Брюссель угрожает санкциями. С другой стороны, на примере Молдавии или Украины видно, что разнообразные форматы вовлечения и грантовой поддержки достигают конкретных результатов, которые заключаются, в частности, в том, что удаётся переориентировать на Запад представителей органов власти, политические структуры, общественный сектор, СМИ, научно-экспертное сообщество. Страны не добиваются впечатляющих результатов в экономике, применяемые ими политические практики далеки от идеальных ${ }^{1}$, внутренние социальные расколы подчас лишь усугубляются, однако достаточная для принятия соответствующих решений часть властных групп, а также значительная часть граждан вовлекаются в систему западных политических ориентиров.

В этой связи отсутствие гуманитарной компоненты превращается в стратегический минус, слабость ЕАЭС, делает его более восприимчивым к негативному внешнему воздействию. Именно в этой сфере сегодня разворачивается наиболее активная конкуренция внешних игроков на постсоветском пространстве. Фактически гуманитарный трек становится приоритетным полем борьбы за влияние в регионе.

В основе западной модели гуманитарного влияния - "выращивание" лояльного "гражданского общества" в целевой стране. Подобный опыт широко реализован на Украине, в Грузии, Молдавии, Киргизии, в несколько меньших масштабах - в Армении и Казахстане, постепенно распространяется в Белоруссии. Ведётся

\footnotetext{
${ }^{1}$ Проведённое немецкими и швейцарскими учеными исследование за счёт средств из фондов ЕС выявило отсутствие "систематического эффекта" в развитии демократических институтов и госуправления в постсоветских странах, вовлеченных в политику соседства ЕС. В восточноевропейских странах, ставших членами ЕС, способность Брюсселя обеспечить соответствие стандартам демократии и государственного управления снижается [Börzel, Schimmelfennig. 2017].
} 
целенаправленная системная работа по созданию инфраструктуры подготовки и поддержки гражданских активистов, экспертных структур, разного рода НКО, а также сопровождающей сети СМИ.

Фактически, реакцией ЕС на украинский кризис стало наращивание ресурсной подпитки в гуманитарной сфере. Так, в 2016 г. 4 тыс. студентов и преподавателей из стран ВП получили стипендии для обучения в ЕС, около 10 тыс. молодых граждан приняли участие в программах обмена ${ }^{1}$. Для сравнения: за весь период 2007-2013 гг. было выделено 5,8 тыс. стипендий ${ }^{2}$. С 2009 г. по настоящее время ЕС выделил 1,5 млрд евро более 100 тыс. компаний, представляющих малый и средний бизнес в странах ВП ${ }^{3}$.

Поступательно наращивается финансовая подпитка Евросоюзом гражданского общества в странах ВП. В 2007-2010 гг. на эти цели было выделено 30 млн евро, в 2011-2013 гг. - 68 млн евро и в 2014-2017 гг. - уже 148 млн евро 4 . За 7 лет рост в 4 раза. Помощь получили более 600 организаций в странах-участницах ВП. В 2017-2020 гг. на эти цели запланировано направить 180 млн евро 5

Что касается китайской инициативы “Пояса и пути”, то она также демонстрирует комплексный характер, увязывая вопросы экономики, гуманитарной сферы и безопасности, что отчетливо заметно на постсоветском пространстве. Пекин отводит "мягкой силе" значимое место. Так, общий объём инвестиций Китая в Белоруссию в 2017 г. составил 271,9 млн долл. (менее 3\% от всех иностранных инвестиций в страну). Для сравнения: объём российских инвестиций в 2017 г. составил 3,6 млрд долл. ${ }^{6}$ При этом, в Беларуси созданы четыре Института Конфуция при ведущих вузах (больше в СНГ только в граничащем с КНР Казахстане - 5) и 7 классов Конфуция (средняя школа) ${ }^{7}$. В 2014 г. образована межправительственная китайско-белорусская комиссия по сотрудничеству в области образования. Она занимается не только формированием нормативно-правовой базы, но и содействием реализации конкретных межвузовских проектов, в том числе академи-

${ }^{1}$ EU's eastern partnership needs revival. EU Observer. 14 Nov. 2017. URL:

https://euobserver.com/opinion/139856

2 Implementation report of Work Programme 2014-2017. 6th Progress Report: June 2016-

December 2016. European Commission. URL:

https://ec.europa.eu/education/sites/education/files/2016-eastern-partnership-meeting-report-

6_en.pdf

${ }^{3}$ EU is Strengthening Businesses in Eastern Partner Countries. 2017. URL:

www.consilium.europa.eu/media/31411/eap-business-forum-factsheet.pdf

${ }^{4}$ Civil Society. At the Heart of the Eastern Partnership. EU Neighbours East. Jun. 2016. https://www.euneighbours.eu//sites/default/files/publications/2017-

01/EaP\%20Civil\%20Society.pdf

${ }^{5}$ Eastern Partnership Civil Society. 2017. URL: www.consilium.europa.eu/media/31412/eap-civilsociety-factsheet.pdf

${ }^{6}$ Иностранные инвестиции // Беларусь в цифрах. Статистический справочник. Минск: Национальный статистический комитет Республики Беларусь, 2018. С. 63-65.

7 Belarus, China interested in developing youth, student cooperation // Belta. 30.09.2016. URL: eng.belta.by/president/view/belarus-china-interested-in-developing-youth-student-cooperation94982-2016/

Современная Европа, 2018, №6 
ческой мобильности, созданием научных центров и лабораторий, подготовкой к открытию в стране новых центров Конфуция и др. Серьёзных масштабов достиг обмен делегациями госорганов, академических институтов, вузов, СМИ, предпринимателей, спонсируемый преимущественно китайской стороной.

Китай весьма активен на постсоветском пространстве. В экспертной среде обсуждаются риски переноса "грязных производств" из Китая в страны Центральной Азии или уступка Таджикистаном части территории КНР в районе Восточного Памира. Член Госсовета КНР, министр общественной безопасности Китая Го Шэнкунь в мае 2017 г. выразил надежду, что партнёры КНР в рамках инициативы "Пояс и путь" "усвоят идею совместной безопасности" и будут "развивать механизм сотрудничества в сфере безопасности"1.

В июле 2017 г. китайская сторона на официальном уровне поставила вопрос об участии КНР в обеспечении безопасности на территории индустриального парка "Великий камень" под Минском, который возводится на средства КНР. По официальным данным, более $50 \%$ рабочих, возводящих объект - граждане Китая (по неофициальным оценкам, эта цифра значительно выше). Начальник политбюро Министерства общественной безопасности КНР Ся Чунюань на встрече с руководством МВД Белоруссии предложил помощь по охране общественного порядка в индустриальном парке, отметив незнание белорусскими правоохранителями китайского языка и менталитета и выразив надежду, что “будет создан пример типичного сотрудничества и образец для взаимодействия в других сферах" [Беларусь посетила делегация..., 2017]. В результате складываются предпосылки для формирования на пространстве Союзного государства России и Беларуси, которое выступает по сути интеграционным ядром ЕАЭС, своеобразной экстерриториальной зоны с экономическими льготами, иностранной рабочей силой и особым режимом безопасности.

На постсоветском пространстве борются центробежные и центростремительные тенденции. С одной стороны, в рамках ЕАЭС возможна реинтеграция и модернизация экономик с перспективой выхода на более широкие объединительные форматы, такие как Большое евразийское партнёрство. С другой стороны, фрагментация постсоветского пространства в целом возрастает (свежий пример - Apмения, где политическая борьба далека от завершения, несмотря на назначение нового премьер-министра). Нет оснований рассчитывать, что в ближайшие годы процесс фрагментации постсоветского пространства, борьбы различных интересов и интеграционных групп ослабеет. В этих условиях важно наряду с укреплением экономической интеграции усилить работу по гуманитарному треку, прежде всего, вместе с союзниками по ЕАЭС.

Гуманитарные проекты в рамках ЕАЭС и СНГ требуют серьёзного анализа, инвентаризации и “пересборки”. Многие программы реализуются долгие годы по инерции, буксуют и не могут предложить содержание, интересное молодёжи и активным социальным группам.

${ }^{1}$ Китай надеется на сотрудничество по безопасности в рамках Шелкового пути // Forbes Казахстан. 5 мая 2017. URL: https://forbes.kz/news/2017/05/05/newsid_143433

Современная Европа, 2018, №6 
Гуманитарная сфера приобретает всё большее значение для руководства постсоветских стран, стремящихся выстраивать и укреплять свою идентичность. Российскую сторону не всегда слышат, когда речь идёт об усилении гуманитарной составляющей евразийской интеграции. Тем не менее, этот вопрос необходимо продолжать корректно, системно ставить. Без взаимного “построения смыслов", без взаимного сближения на широком общественном уровне, без запуска программ эффективного гуманитарного сотрудничества интеграционный проект рискует утратить динамику.

В подписанных соглашениях ЕС с Казахстаном (2014 г.) ${ }^{1}$ и Арменией $(2017$ г. $)^{2}$ важное место занимают вопросы культуры, образования и гражданского общества. В них, в частности, ставятся задачи “конвергенции образовательных стандартов" ЕС и Казахстана или перехода системы образования Армении на стандарты ЕС. Ещё более выраженную роль данные сюжеты играют в программе ЕС "Восточное партнёрство”, где участвуют члены ЕАЭС Армения и Беларусь.

Страны ЕАЭС стремятся адаптировать западные практики, в том числе и в гуманитарной сфере, руководствуясь часто прагматичными соображениями. Важно, чтобы это движение дополнялось развитием гуманитарного сотрудничества внутри ЕАЭС, если государства - участники настроены стратегически на повышение эффективности союза. Без формирования общего гуманитарного пространства отношения в рамках союза будут уязвимы для экономических проблем и информационных манипуляциями. Важно шире применять проектный подход, нацеленный на взаимодействие и поддержку социально активных групп и совместных проектов со странами ЕАЭС и СНГ - не только в области экономики, но и малого и среднего бизнеса, межрегионального сотрудничества, академических обменов, конкурсов, стажировок, работы с общественным сектором и экспертным сообществом. Важно вывести эту работу на регулярную основу, содействовать появлению эффективных проектных команд, создавать общие источники финансирования (как на многосторонней основе в рамках ЕАЭС, так и двусторонней основе с отдельными странами), позволяющие развивать институты гражданского общества не "против" интеграции, а "вместе" с ней.

Учитывая тенденции поступательного укрепления в гуманитарной сфере постсоветского пространства внешних игроков с последующей конвертацией влияния в сфере политики и безопасности (особенно зримо это наблюдается в западной части постсоветского пространства, хотя не ограничивается ею), форми-

\footnotetext{
${ }^{1}$ В соглашении, в частности, закреплена необходимость реформ системы образования Казахстана и её “конвергенция с политиками и практиками Евросоюза”. В перечень сфер сотрудничества включена межведомственное сотрудничество, мобильность студентов и преподавателей (ст. 244). Подробнее: Official Journal of the European Union. Legislation. 4 Feb. 2016. Vol. 59. URL: https://eeas.europa.eu/sites/eeas/files/enhanced_partnership_and_cooperation_agreement.pdf

${ }^{2}$ Comprehensive and Enhanced Partnership Agreement between the European Union and the European Atomic Energy Community and their Member States, of the one part and the Republic of Armenia, of the other part. 2017. URL: https://eurlex.europa.eu/resource.html?uri=cellar:fab8df35-a1e2-11e7-a56f01aa75ed71a1.0019.02/DOC_2\&format=PDF 
рование общих подходов в гуманитарной сфере становится одним из элементов обеспечения коллективной безопасности стран региона.

\section{Список литературы}

Беларусь посетила делегация Министерства общественной безопасности Китайской Народной Республики во главе с начальником Политбюро МОБ КНР Ся Чунюанем. МВД Республики Беларусь. 25 июля 2017. URL: mvd.gov.by/main.aspx?guid=199083

Выступление В.В. Путина на 70-й сессии Генеральной Ассамблеи OOH. 2015. URL: kremlin.ru/events/president/news/50385

Гегелашвили Н.А. (2018) Политика США на постсоветском пространстве // Постсоветское пространство: роль внешнего фактора. Сб. ст. / Отв. ред.: А.Б. Крылов, А.В. Кузнецов, Г.И. Чуфрин. - М.: ИМЭМО РАН. С. 95-111.

Громыко Ал.А. (2016) Структуры соперничества и опыт истории // Современная Европа. № 4. C. 6-20.

Громыко Ал.А. (2018) Большая Европа: внутренние и внешние угрозы безопасности // Вестник Российской академии наук. Т.88, №5. С. 416-429.

Данилов Д.А. (2017) Глобальная стратегия ЕС: восточный вектор. // Современная Европа. № 3. C. $10-21$.

Кондратьева Н.Б. (2018) Отношения ЕС - ЕАЭС: особенности современного этапа. // Современная Европа. №3. С. 60-70.

Концепция внешней политики Российской Федерации (утверждена Президентом Российской Федерации В.В.Путиным 30 ноября 2016 г.). URL: www.mid.ru/foreign_policy/news//asset_publisher/cKNonkJE02Bw/content/id/2542248 (дата обращения: 14.08.2018)

Обращение Президента России к главам государств - членов Евразийского экономического союза. 2018. URL: kremlin.ru/events/president/news/56663

Путин В.В. (2017) “XXV саммит АТЭС в Дананге: вместе к процветанию и гармоничному развитию". URL: kremlin.ru/events/president/news/56023

Состоялась рабочая поездка Секретаря Совета Безопасности Российской Федерации Николая Патрушева в Республику Казахстан. URL: www.scrf.gov.ru/news/allnews/845/ (Дата обращения: 14.08.2018).

\section{References}

Belarus' posetila delegacija Ministerstva obshhestvennoj bezopasnosti Kitajskoj Narodnoj Respubliki vo glave s nachal'nikom Politbjuro MOB KNR Sja Chunjuanem. MVD Respubliki Belarus'. 25 ijulja 2017. URL: mvd.gov.by/main.aspx?guid=199083

Vystuplenie V.V. Putina na 70-j sessii General'noj Assamblei OON. 2015. URL: kremlin.ru/events/president/news/50385

Gegelashvili N.A. (2018) Politika SShA na postsovetskom prostranstve // Postsovetskoe prostranstvo: rol' vneshnego faktora. Sb. st. / Otv. red.: A.B. Krylov, A.V. Kuznecov, G.I. Chufrin. - M.: IMEMO RAN. C. $95-111$.

Gromyko Al.A. (2016) Struktury sopernichestva i opyt istorii // Sovremennaja Evropa. № 4. S. 6-20.

Gromyko Al.A. (2018) Bol'shaja Evropa: vnutrennie i vneshnie ugrozy bezopasnosti // Vestnik Rossijskoj akademii nauk. T.88, №5. S. 416-429.

Danilov D.A. (2017) Global'naja strategija ES: vostochnyj vektor. // Sovremennaja Evropa. № 3. S. $10-21$.

Kondrat'eva N.B. (2018) Otnoshenija ES - EAJeS: osobennosti sovremennogo jetapa. // Sovremennaja Evropa. №3. S. 60-70.

Koncepcija vneshnej politiki Rossijskoj Federacii (utverzhdena Prezidentom Rossijskoj Federacii V.V.Putinym 30 nojabrja 2016 g.). URL: www.mid.ru/foreign_policy/news//asset_publisher/cKNonkJE02Bw/content/id/2542248 (data obrashhenija: 14.08.2018)

Obrashhenie Prezidenta Rossii k glavam gosudarstv - chlenov Evrazijskogo jekonomicheskogo sojuza. 2018. URL: kremlin.ru/events/president/news/56663

Putin V.V. (2017) "XXV sammit ATJeS v Danange: vmeste k procvetaniju i garmonichnomu razvitiju". URL: kremlin.ru/events/president/news/56023

Современная Европа, 2018, №6 
Sostojalas' rabochaja poezdka Sekretarja Soveta Bezopasnosti Rossijskoj Federacii Nikolaja Patrusheva v Respubliku Kazahstan. URL: www.scrf.gov.ru/news/allnews/845/ (Data obrashhenija: 14.08.2018).

Börzel T., Schimmelfennig F. (2017) Coming together or drifting apart? The EU's political integration capacity in Eastern Europe // Journal of European Public Policy. Vol. 24. P. 278-296.

Browning C. (2018) Geostrategies, geopolitics and ontological security in the Eastern neighbourhood: The European Union and the 'new Cold War' // Political Geography. Vol. 62. P. 106-115.

Comprehensive and Enhanced Partnership Agreement between the European Union and the European Atomic Energy Community and their Member States, of the one part and the Republic of Armenia, of the other part. 2017. URL: https://eur-lex.europa.eu/resource.html?uri=cellar:fab8df35-a1e2-11e7-a56f01aa75ed71a1.0019.02/DOC_2\&format=PDF

Eurasian Economic Union: The rocky road to integration. European Parliamentary Research Service, 2017. URL:

www.europarl.europa.eu/RegData/etudes/BRIE/2017/599432/EPRS_BRI(2017)599432_EN.pdf

Joint declaration. By the President of the European Council, the President of the European Commi ssion, and the Secretary General of the North Atlantic Treaty Organization. 8 Jul. 2016.URL: http://www.nato.int/cps/en/natohq/official_texts_133163.htm?selectedLocale=en

Kaczmarski M. (2017) Non-western visions of regionalism: China's New Silk Road and Russia's Eurasian Economic Union // International Affairs. Vol. 93. P. 1357-1376.

Remarks by NATO Secretary General Jens Stoltenberg at a press point with the President of Georgia, Giorgi Margvelashvili (NATO Summit Brussels). 12 Jul.2018. URL:

https://www.nato.int/cps/en/natohq/opinions_156735.htm

Remarks by President Donald Tusk following the first day of the European council meeting. 21/06/2016.URL: http;//www.consilium.europa.eu/en/press-rleases/2016/10/20-tusk-remarks-pressconference/

Shared Vision, Common Action: A Stronger Europe. A Global Strategy for the European Union's Foreign and Security Policy. 2016. URL:

http://eeas.europa.eu/archives/docs/top_stories/pdf/eugs_review_web.pdf

\title{
"Competition of Integrations" in the Post-Soviet Space: Humanitarian Dimension
}

Author. Smirnov V., Candidate of Political Science, Institute of Europe, Russian Academy of Sciences. Address: 11-3, Mokhovaya street, Moscow, Russia, 125009. E-mail: vsmirnov@kantiana.ru

\begin{abstract}
The article deals with the processes of interaction between various integration projects in the Post-Soviet space in the context of creation of Eurasian Economic Union (EAEU). The underlying causes for the evolution of regional situation in the logic of "competition of integrations" rather than "integration of integration" are explained. Special attention is paid to the analysis of latest tendencies in the humanitarian (soft power) footprint of European Union and China in the Post-Soviet region. Drawing on various sources of data, the author assesses the efficiency of certain components of EU and China's soft power in the region. The paper contributes to the research of contemporary tools and trends in soft power and humanitarian cooperation, and makes the case for considering the humanitarian dimension as an inherent element of security. Recommendations are put forward regarding the necessity to expand humanitarian cooperation in EAEU and CIS, to reconstruct necessary approaches and institutions in this dimension in order to enhance these organizations' competitiveness in comparison with other external strategies.
\end{abstract}

Key words: Post-soviet space, integration, security, humanitarian cooperation, soft power, Eurasian Economic Union, European Union, China, USA, NATO.

DOI: http://dx.doi.org/10.15211/soveurope620185161 